\title{
Emerging priorities in reproductive, maternal, and newborn health
}

Population Council

Follow this and additional works at: https://knowledgecommons.popcouncil.org/departments_sbsr-rh

Part of the Demography, Population, and Ecology Commons, Family, Life Course, and Society Commons, International Public Health Commons, Maternal and Child Health Commons, and the Women's Health Commons How does access to this work benefit you? Let us know!

\section{Recommended Citation}

"Emerging priorities in reproductive, maternal, and newborn health," fact sheet. Washington, DC: Population Council, 2015. 


\section{FACTS ABOUT PE/E}

\section{Ending Eclampsia seeks to expand access to proven, underutilized interventions and commodities for the prevention, early detection, and treatment of pre- eclampsia and eclampsia (PE/E) and strengthen global partnerships}

Ending Eclampsia is working in Nigeria and Bangladesh to assess the level of program activities, gaps and challenges around prevention and treatment of PE/E and magnesium sulfate $\left(\mathrm{MgSO}_{4}\right)$. The project will build upon this landscape analysis to expand services to detect and manage $\mathrm{PE} / \mathrm{E}$, develop and support implementation of strategic plans for replicating the intervention package, and increase global PE/E evidence shared through knowledge and learning platforms.

Ending Eclampsia's legacy will be:

- A dramatically enlarged and robust body of evidence-synthesized, translated, and shared through global knowledge and learning networks-that informs strategies to scale up underutilized yet effective PE/E interventions in low resource settings.

- Greatly expanded implementation of underutilized interventions, commodities and approaches in targeted countries to substantially increase access to services for the prevention and treatment of $\mathrm{PE} / \mathrm{E}$ as the result of improved programming that addresses the ability to apply and to monitor the scale up of high impact practices.

- The adoption of improved PE/E programming in countries where Ending Eclampsia did and did not undertake work, as the result of its global thought leadership and coordination

- Strengthened capacity of local institutions to support scale up of defined PE/E interventions.

Ending Eclampsia will contribute to the goal of reducing maternal morbidity and mortality caused by PE/E with the objective to increase appropriate prevention and treatment of severe PE/E in USAID priority countries.
- Each day, about 800 women die from preventable causes related to pregnancy and childbirth

- The second most frequent direct cause of maternal mortality is a result of pregnancy-induced high blood pressure leading to $\mathrm{PE} / \mathrm{E}$

- Babies born prematurely, due to their mothers experiencing $\mathrm{PE} / \mathrm{E}$ are also at higher risk of dying

- Women in developing countries are $\mathbf{3 0 0}$ times more likely to die from eclampsia than women in developed countries

- The World Health Organization recommends magnesium sulfate as the safest, most effective, and lowest-cost treatment for severe pre-eclampsia and eclampsia

- The need for magnesium sulfate is greatest in low-income countries of sub-Saharan Africa and South Asia, where pregnancy and childbirth are less safe and $65 \%-85 \%$ of the population is rural, with limited access to lifesaving health care
The Population Council conducts research and delivers solutions that improve lives around the world. Big ideas supported by evidence: It's our model for global change. popcouncil.org

(C) 2015 The Population Council, Inc.
Made possible by the generous support of the American people through the United States Agency for International Development (USAID).
POPULATION COUNCIL

Ideas. Evidence. Impact. 


\section{PROJECT DEVELOPMENT HYPOTHESIS}

Ending Eclampsia has a clear project development hypothesis. It is assumed that if the capacity of frontline primary health care $(\mathrm{PHC})$ providers is improved, for detecting and managing PE/E particularly during the ANC period, key policy barriers will be removed: a loading dose of $\mathrm{MgSO}_{4}$ is provided at the PHC level, use of aspirin prescribed to pregnant women who are at risk of developing PE/E, appropriate use of antihypertensive medication for pregnant women with raised blood pressure, then there will be early diagnosis of PE/E; and use of low-cost underutilized effective intervention for the management of $\mathrm{PE} / \mathrm{E}$, which will ultimately reduce the morbidity and mortality of mothers and newborns. Our development hypothesis relies on the assumption that if the quality of care at the PHC level for pregnant women can be improved, use of $\mathrm{MgSO}_{4}$ for the management of $\mathrm{PE} / \mathrm{E}$ is ensured and the knowledge and skills are included in the PHC service providers' curriculum there will be sustainable improvement in the provision of maternal and newborn health.

\section{LEVELS OF PROGRAM IMPLEMENTATION}

Interventions will be implemented at four levels:

- Community level

- Primary Health Care (PHC) level

- Referral level facilities

- Policy level

In addition, there are various categories of providers such as physicians, paramedics, nurse/midwives and fieldworkers that would be involved in providing the loading dose depending on the Ministry of Health $(\mathrm{MoH})$ approval. The project activities will be implemented in partnership with national obstetrics and gynecology (Ob/Gyn) and midwifery societies in each country.

\section{IMPLEMENTATION COUNTRIES}

The interventions will initially be implemented in Bangladesh and Nigeria and, subsequently, the learning from these two countries will be validated and scaled up or replicated in Ethiopia and Pakistan in Year Two of the project. The evidence generated from each country will be fed into the global evidence repository for disseminating through knowledge and learning networks to facilitate use of high-quality underutilized interventions and commodities and to reduce maternal mortality and morbidity around the globe particularly in USAID priority countries.

\section{LANDSCAPE ANALYSIS}

From PE/E perspective, we describe landscaping analysis as a form of analysis to understand the overall policies, programs and service environment around PE/E in a particular geographical area be it nation, state or local district level. The primary goals and objectives of the landscape analysis are to identify the policy and program level activities; gaps and challenges around prevention and treatment of $\mathrm{PE} / \mathrm{E}$, using loading dose of $\mathrm{MgSO}_{4}$ at the PHC level, aspirin prophylaxis and use of antihypertensive in pregnancy at the national level in each country.

We will also review the extent to which non-government organizations, development partners and others (including professional associations) are involved in $\mathrm{PE} / \mathrm{E}$ activities, the policy makers, stakeholders' and service providers understanding of $\mathrm{PE} / \mathrm{E}$ and use of loading dose of $\mathrm{MgSO}_{4}$ in the management of PE/E. The $\mathrm{PE} / \mathrm{E}$ patients' perspective will also be gathered to feed into the landscaping analysis.

\section{SCALING UP}

The project will promote and support effective use of evidence that can be used to support institutionalization and scale-up of identified best practices. Scaling up is defined here as

\section{"efforts to increase the impact of innovations successfully tested in pilot or experimental projects so as to benefit more people and to foster policy and programme development on a lasting basis"}

-EXPANDNET/WHO, 2008

Ending Eclampsia project will share lessons with $\mathrm{MOH}$ staff and partners working in $\mathrm{PE} / \mathrm{E}$ in each target country and use the ExpandNet/WHO scale up framework to ensure a coordinated approach to scaling up and to understand lessons and evidence on best practices. Regional workshops will be conducted using the ExpandNet 'nine steps for scaling up a strategy' as a guide to encourage a context specific strategy that is flexible to respond to innovations from individual countries. One of the nine steps focuses on Monitoring and Evaluation; Ending Eclampsia will document scale up activities through a country case study approach and use of the WHO quality of care indicators.

\section{IMPACT}

Findings from Ending Eclampsia will change the global conversation on maternal mortality, putting a greater focus on this preventable cause of death and will be used to improve access to life-saving care for the approximately 3 million women at risk of pre-eclampsia and eclampsia every year.

Please address any inquiries about the Ending Eclampsia project to Charlotte E. Warren, the project director: cwarren@popcouncil.org.

www.popcouncil.org/research/ending-eclampsia1 